rian cyst filled the whole abdomen, from the sternum downwards. It had only been of two years' growth, and the increase of late had been rapid. She was admitted on April 8th, and the operation was performed on the 13 th, Dr. Giles, Dr. Llewellyn Williams, and others, being present. Mr. Parson gave chloroform. Some very firm parietal adhesions were separated, and a large cyst was emptied. As it was withdrawn, a long coil of small intestine was found to be adhering to it by its mesentery. This was carefully separated, and it was then found that the proper pedicle could not be safely separated from the cæcum above or the bladder below; the clamp was accordingly placed round the neck of the cyst rather than on the pedicle. A little blood which had escaped from the torn adhesions was then sponged away, and the wound closed as usual. On the third day the clamp was removed. On the 18th of May she left the hospital. The fluid and solid portions of the tumour removed weighed together thirty-seven pounds.

CASE 5. Ovariotomy; bronchitis ; venesection; recovery.S. B- unmarried, aged nineteen, was sent to Mr. Wells by Mr. Rumsey, of Cheltenham, as a very favourable case for ovariotomy. The abdomen was filled by an ovarian cyst, nearly unilocular, free from adhesions, and she was otherwise healthy. She was admitted April 17th, and the operation was performed on the 22nd, a week after the cessation of the catamenia. Mr. Parson gave chloroform. Dr. Boulton of Horncastle, Mr. Macilwain, and other gentlemen were present. The operation was of the simplest possible description. An incision four inches long exposed a non-adherent cyst, which was tapped, and withdrawn as it was emptied. A small pedicle on the left side was secured by a clamp, the cyst cut away, the right ovary felt to be healthy, and the wound closed by sutures, without the slightest exposure of any of the viscera. The stitches were removed on the $24 \mathrm{th}$, when the wound was quite healed. On the 25 th bronchitis set in, and was obstinate for a few days. Notwithstanding the persistent cough, the abdominal wound healed perfectly, and she never complained of the slightest pain in the abdomen. The clamp was removed on the 1st of May. She was quite convalescent fourteen days after the operation, and left the hospital in good health on May 23rd.

\section{LONDON SURGICAL HOME.}

\section{MULTILOCULAR OVARIAN DROPSY OF LEFT OVARY ; OVARIOTOMY ; RECOVERY.}

(Under the care of Mr. BAKER BRowN.)

Mrs. C-, aged fifty-five, married, was admitted Oct. 15th, 1862. She has been married thirty-three years, and has had eleven children-all boys; always enjoyed good health until three years ago, when she first noticed an enlargement of the abdomen; has never suffered much pain, but her womb has always come down during the last three years. She did not increase very rapidly in size until the last few months; has never been tapped; has menstruated regularly up to last October. Her general health has suffered much lately.

An examination showed a very large multilocular ovarian tumour. The thoracic organs were much displaced, causing great discomfort. She was extremely emaciated; but had a cheerful countenance, and expressed great desire for extirpation to be performed.

The operation was performed on Dec, 4 th, 1862. The patient having very much improved under the usual preparatory treatment, she was this day placed under the influence of chloroform, which she took very well. The incision was about three inches and a half long, and the abdominal parietes being very thin, the tumour was soon reached and punctured, and forty. six pints of fluid drawn off. There were no adhesions, and the pedicle, which was long, was fastened by callipers, and the wound closed by silver-wire sutures. The tumour was com. posed principally of three cysts, each of which, however, con tained many smaller ones.

The patient never had a bad symptom, and made a good recovery. The callipers were removed from the pedicle on the 8 th of December, and the wire sutures on the 12th.

Since the occurrence of the foregoing there have been no further operations of ovariotomy in the London Surgical Home, chiefly on account of erysipelas breaking out in the old building, necessitating the closure of several of the wards, and also from the confusion consequent upon moving into another and much larger building close to the original institution.

\section{ST. THOMAS'S HOSPITAL.}

POLYCYSTIC OVARIAN TUMOUR OF FOUR YEARS' STANDING, SUCCESSFULLY REMOVED BY OVARIOTOMY.

(Under the care of Mr. Simon.)

$\mathrm{W}_{\mathrm{E}}$ have been furnished with the following notes of the case :-

A. W-, aged twenty-two, single, a servant, observed about four years and a half ago a slight but persistent swelling on the right side of the abdomen, the periodical return of the menses ceasing about the same time. From that date the tumour slowly but progressively increased, its development being unattended by constitutional symptoms, and the patient continuing to enjoy tolerable health. She was admitted under the care of Dr. Bennett on the 2nd of November, 1861 , nearly three years after she had noticed the first appearance of the tumour. The disease being diagnosed as one of ovarian dropsy, the patient was shortly afterwards tapped, and half a pint only of clear fluid evacuated. The size of the abdomen was not appreciably diminished by the operation, and the patient left about a fortnight afterwards, being still in a fair state of bealth, and promising to return at the end of a month or six weeks to undergo the operation of ovariotomy, this measure being considered advisable by Dr. Bennett.

Circumstances, however, prevented her returning until Nov., 1862 , when she came under the care of Dr. Brinton, suffering at the time from an attack of chronic diarrbcea, by which she was considerably reduced in strength. The condition of the tumour had not much altered since the time of her first admission, the size of the abdomen being, nevertbeless, decidedly, though not greatly, increased. With tonics and astringents her condition gradually improved, the diarrhcea ceasing, and her strength partially returning. Under these circumstances it was decided by Mr. Simon, to whose care the patient was transferred, to operate on Feb. 17th, 1863.

The girth of the patient was now forty-eight inches, and the distance from the umbilicus to the pubes over twelve inches. Before removal to the theatre, the bladder was emptied, and she was placed under the influence of chloroform. The temperature of the theatre was raised to $75^{\circ}$. An incision four inches long was made below the umbilicus, and the tumour readily exposed. The incision was further extended upwards, so that its total length was seven inches and a half. The tumour was then grasped and drawn forwards by forceps. Its walls were so thin that they were torn through, and the fluid contents began to pour out, but were prevented entering the abdomen by heated flannels, by which all access to the general peritoneal cavity was shut off. Mr. Simon now introduced his hand, and turned out the tumour upon the abdomen. Two omental adhesions above were tied with silver wire, cut close, and returned into the abdomen. The pedicle, of large size, containing several large vessels, was drawn forwards, a clamp applied to it, and divided. The edges of the wound were closed with silver sutures. The diseased ovary consisted of three large cysts, one of which only had been emptied through the canula; it was about a foot in diameter, and its total contents measured three gallons.

The patient appeared somewhat but not greatly exhausted by the operation. She vomited three times during the next. two hours; shortly afterwards she slept for an hour. At seven. P. M. she was restless, but slept for three hours. During the night she was more comfortable.

Feb. 28th. - Passed a very good day, taking beef-tea, mili or egg, and brandy at intervals; and was free from pain and tenderness.

March 1st.-_Slept fairly, feeling refreshed. The clamp was removed and the wound dressed; wound healed throughout its greater part. From this period the progress of the patient towards recovery was rapid, and unmarked by a single adverse symptom. The sutures were all removed on March 4th, and she left the hospital some short time afterwards quite convalescent.

A noteworthy feature in this case was the small amount of constitutional disturbance which followed the operation.

ImPROVED Health of London. - In the ten yearg, $1840-49$, the average annual rate of mortality in London was $25 \cdot 1$ per thousand: in the subsequent decennium, 1850-59, it fell to 23.6 per thousand. Under the projected improvements, among which may be prominently noticed the purification of the Thames by the establishment of the main drainage, London will probably be one of the healthiest districts in the kingdom 